\title{
Analysis of results of nonunion tibial fractures Ilizarov external fixation
}

\section{Pandillapalli Devanatha Reddy, Koramutla Harsha Kumar*}

Department of Orthopaedics, Narayana Medical College, Nellore, Andhra Pradesh, India

Received: 15 June 2018

Revised: 20 July 2018

Accepted: 21 July 2018

\section{*Correspondence:}

Dr. Koramutla Harsha Kumar,

E-mail: drharshaortho@gmail.com

Copyright: ( ) the author(s), publisher and licensee Medip Academy. This is an open-access article distributed under the terms of the Creative Commons Attribution Non-Commercial License, which permits unrestricted non-commercial use, distribution, and reproduction in any medium, provided the original work is properly cited.

\begin{abstract}
Background: Tibia is most exposed bone in the body and vulnerable to trauma and therefore its fractures are common among the long bone fractures. Tibia is the common site of non-union in long bone fractures. Management of non-union in long bone fractures is a challenging problem for orthopedic surgeons. When the defect is more than 4 $\mathrm{cm}$ then it needs bone transport.

Methods: Materials of this study comprised 20 cases of nonunions of tibia treated over $2 \frac{1 / 2}{2}$ years period from June 2006 to December 2009 in the Department of Orthopedics at Narayana Medical College, Nellore, Andhra Pradesh. This was a prospective study of nonunions of tibia treated by Ilizarov ring external fixators and incidental surgery.

Results: Out of 20 tibial non-unions, in 15 patients the fixator has been removed. In 4 patients the fracture had united but the fixators are in situ and they are in consolidation phase and the remaining 1 patient is in various stage of follow up. The results of the 15 patients in whom the fixators have been removed are studied. The hospitalization time from 15 days to 120 days. The average hospital duration is 44.04 days. The total time ranged from 4 months to 15 months. Average time is 9.25 months.

Conclusions: From this study we conclude that Ilizarov external fixator is a reliable, versatile and effective treatment for the treatment of tibia nonunion fractures.
\end{abstract}

Keywords: Tibia, Trauma, Fractures

\section{INTRODUCTION}

Tibia is most exposed bone in the body and vulnerable to trauma and therefore its fractures are common among the long bone fractures. ${ }^{1}$ Tibia is the common site of nonunion in long bone fractures. ${ }^{2}$ Management of non-union in long bone fractures is a challenging problem for orthopedic surgeons. When the defect is more than $4 \mathrm{~cm}$ then it needs bone transport. Bone transport can be done by ring fixators, modified arbeitsgemteinschaftfur Osteosynthesefragen (OA) fixators or specialized intramedullary nails. The ring fixators, i.e. Illizarov fixators was developed by gavriil Abramovich Ilizarov in Kurgan, Western Siberia, USSR in 1951 for the fixation of fractures. Illizarov's greatest contribution, however was pioneering the sense of bone and soft tissue regeneration under tensile forces and this is called theory of tension stress. ${ }^{3}$

\section{METHODS}

Materials of this study comprised 20 cases of nonunions of tibia treated over $2 \frac{1}{2}$ years period from June 2006 to December 2009 in the Department of orthopedics at Narayana Medical College, Nellore and Andhra Pradesh. This was a prospective study of nonunions of tibia treated by Ilizarov ring external fixators and incidental surgery. ${ }^{4}$

A total of 20 cases of tibial nonunions were taken up for this study. These include 18 males and 2 females ranging from the 30 to 65 years with a mean age of 47.5 years. 
The etiology of nonunion was open fracture in 15 cases and closed 4 cases and chronic osteomyliters in one case. The level of nonunion was upper $1 / 2$ of shaft of tibia in 2 cases, middle $1 / 2$ in 12 cases and lower $1 / 2$ in 6 cases.

Axial load is in fact the force Ilizarov frame, if correctly applied, can reestablish in bone. After transosseous, osteosynthesis, the reintegration of function in the presence of renewed vascularisation promotes osteogenesis and local tissue trophism.

The corticotomy is the biological stimulus for neovasculisation and the correctly applied external fixator introduces a mechanical environment which facilitates function (loading and mobility). The marriage of revascularization and local tissue trophism under mechanical load has been shown by Ilizarov to reliably heal infected non unions and hypertrophic nonunion is the most difficult challenges. Additionally, deformities such as angulation and shortening can be corrected with Ilizarov methods.

Selection of treatment technique for an infected nonunions depends on various factors, such as the type of nonunion (usually atrophic), the extent of the infection and trophic skin changes. Traditional concepts dictate the devialized bone is were prone to infection, the wider the bone necrosis, the more spread will be the infection.

According to Ilizarov, to eliminate the infection, vascularization of the osteomylitis centre must be increased by the biological stimulation of corticotomy. Osteomylitis burns in the fire of regeneration. In our clinical application of this concept, there was healing of nonunion, but infection was not completely eliminated. Open debridement of the nonunion site to remove the necrotic and infected segments and then proceed for bifocal osteosynthesis, in order to eliminate bone gap.

All cases had at least one previous surgical procedure to treat the original problem or nonunion. The mean number or surgical procedures were 4 with a range up to 7 . The duration of nonunion before Ilizarov treatment ranged from 5 months to 10 years with a mean of 15.8 months.

In addition to bony problems these patients these patients had a variety of soft tissue problems. 8 of 20 had undergone plastic surgery procedures to cover the bone. 5 patients $(25 \%)$ had evidence of preoperative neurovascular damage. Of these patients 4 had foot drop and one had only one single blood vessel either posterior tibial artery or dorsalis pedis artery.

\section{RESULTS}

Out of 20 tibial non-unions, in 15 patients the fixator has been removed. In 4 patients the fracture had united but the fixators are in situ and they are in consolidation phase and the remaining 1 patient is in various stage of follow up. 15 of the 20 cases were classified as atrophic nonunion s bases on their roentigraphic appearance alone. The other 5 were initially classified as hypertrophic.

16 of 20 cases $(80 \%)$ were originally infected and 4 (20\%) were still draining at the start of Ilizarov treatment and were considered to have chronic osteomylitis. 8 of the 20 patients had a fixed deformity at the fracture site. In 10 of 20 patients bone loss was present ranging from 1 $\mathrm{cm}$ to $5.5 \mathrm{~cm}$ with a mean of $3.25 \mathrm{~cm}$.

The results of the 15 patients in whom the fixators have been removed are studied. The hospitalization time from 15 days to 120 days. The average hospital duration is 44.04 days. The total time ranged from 4 months to 15 months. Average time is 9.25 months.

10 patients received monofocal compression distraction technique after correcting deformity if present with appropriate placement of hings. 10 of these patients achieved union. In one patient of this group re fracture occurred after removal of the fixator. In one patient the refracture occurred 15 days after removal of the fixator when tripped and fell down on a slippery surface. This fracture got united 5 months after reapplication of Ilizarov.

In the other patient, the preoperative clinical evaluation and radiographic evaluation showed union. After removal of fixator also clinically the fracture got united. A small infected sinus persisted at the fracture site after the fixator removal. After 3 weeks when the plaster was removed refracture was noticed. The persistent infection of the bone might probably the cause of the fracture.

Bone limb lengthening and bone transport were done in patients and only pure limb lengthening was done after acute docking in 4 patients. The average bone transport done for patient in $5.5 \mathrm{~cm}$ with a range of $2 \mathrm{~cm}$ to $9 \mathrm{~cm}$. The limb lengthening index was $0.72 \mathrm{~cm}$ per month that is for lengthening of $1 \mathrm{~cm}$ of regenerate 41 days were required.

\section{Bony results}

For bone results 4 criteria were evaluated: Union, deformity, infection, limb length discrepancy.

Out of 15 patients, except the patients all others achieved bony union (79.2\%). Out of 8 previously infected and draining patients preoperatively. Only 2 are infected and draining still after the removal of fixator for the follow up examination. Three patients have residual deformity of more than 70.2 patients here got residual inequality more than $1.5 \mathrm{~cm}$.

Excellent bone result: With union, no infection, limb length discrepancy less than $2.5 \mathrm{~cm}$ in tibia, deformity less than $7^{0}$ 
Good: Union + Any 2 of the above 3; Fair: Union + Any one of the above factors; Poor: nonunion or refracture, none of the others.

\section{The functional results were based on 5 criteria:}

Significant limp, equinus or rigidity of ankle, soft tissue dystrophy that is skin hypersensitivity or insensitivity of sole with decubitus ulcer, pain and inactivity- (A. That is unemployment because of leg injury, B. Inability to return to daily activities because of leg injury.)

Excellent result: Active individual with none of the other 4 criteria.

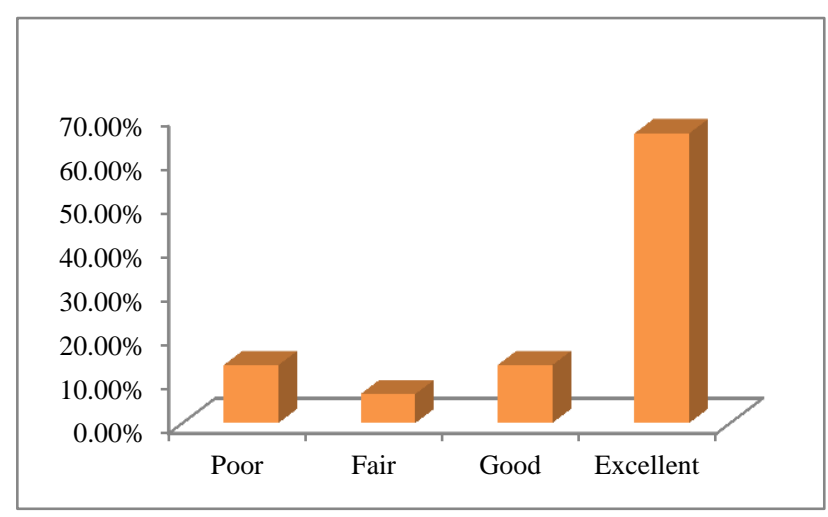

Figure 1: Bony results.

Excellent: 10 (66\%), Good: 2 (13.2\%), Fair: 1 (6.6\%), Poor: 2 (13.2\%).

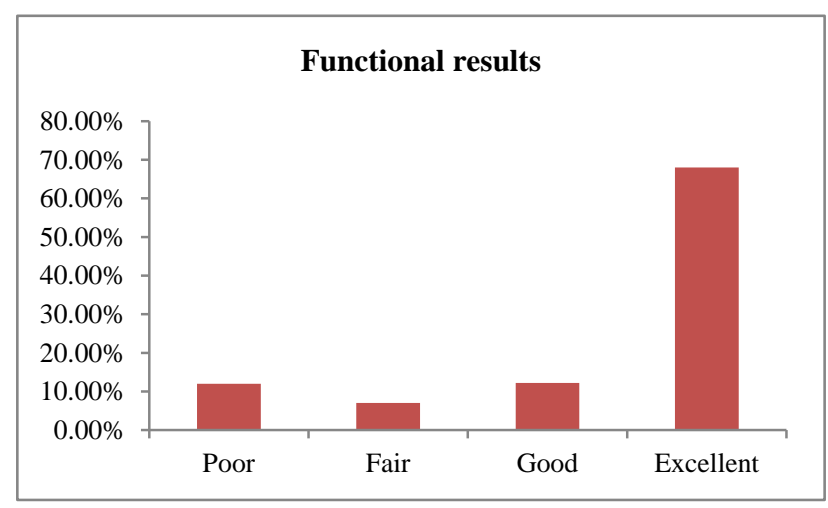

Figure 2: Functional results.

Good result: Active individual with one or two of the other criteria, Fair: Active individual with 3 to 4 other criteria amputations, Poor: Inactive individual.

All patients returned to work and daily activities. 2 patients had significant limp. An uncorrected fixed equinus deformity remained in 2 patients. Soft tissue dystrophy and pain related to preoperative neurologic injury persisted in 2 patients.
Based on these criteria the results were graded as: excellent: 9 (59.4\%), good: 2 (14.76\%), fair: 1 (6.6\%), poor: $3(19.8 \%)$.

Ranges of motion of the knee and ankle before and after treatment are compared. In 7 patients ROM of both knee and ankle improved. In 4 patients only knee ROM improved and in 4 patients only ankle ROM improved. The subtalar joint was stiff before treatment remained so after treatment.

\section{DISCUSSION}

Tibial diaphyseal non unions with associated sequelae may be extremely difficult to resolve. As a consequence, it is not uncommon to have residual deformity, persistent infection, soft tissue contracture prolonged fracture disease or eventual amputation. ${ }^{7}$

The promising new techniques to improve these results appear to be implantation of vascularized bone grafts and free muscle flap coverage; and most recently, the applications of the method ofllizarov. ${ }^{12}$

Most treatment methods that are highly successful at obtaining union cannot address all of these problems and certainly not at the same time. ${ }^{8}$

The creative techniques are destined to failure in infected non unions unless adequate debridement of the infected area and reconstruction of any discontinuity of the bone is not achieved. ${ }^{14}$

Ilizarov circular frame osteosynthesis allows resection of the infected bone area and repair of bone defect by transport of bone segment and stabilization of bone to consolidation, while maintaining or restoring the length of the limb as desired. ${ }^{9}$

The present study deals with 15 patients in whom the fixators were removed. Union was achieved in 13 patients $(85.8 \%)$.

The average chronicity of nonunion prior to Ilizarov surgery was 15.8 months with an average 4 previous surgeries. In the present study excellent bony result was obtained in $66 \%$, good in $13.2 \%$, fair in $6.6 \%$ and poor in $13.2 \%$ of patients.

The experience gained from our patients is early solving their problems helped us to understand the better technique and the early complications were avoided in subsequent patients. ${ }^{11}$

Aaronovich et al from Ilizarov's institution reported on 170 patients treated by the Ilizarov method for tibial bony defects. The chronicity of the nonunions was five to ten years. Sixty four had chronic osteomyelitis. Excellent results comprising union, no infection, leg length discrepancy lea than $3 \mathrm{~cm}$, and no deformity were 
achieved in $68.9 \%, 28.7 \%$ had a fair result only because of persistence of osteomyelitis, $74.8 \%$ had returned to work. $^{17}$

Kuftiryev and Meshkov reported on 154 patients at Ilizarov's institution with femoral body defects ranging from 1 to $23 \mathrm{~cm}$. At follow up evaluation, $147 \mathrm{had}$ achieved union without deformity and with osteomyelitis showed no further drainage.

Voronorich and Volchkevich from minsk, USSR, reported on 80 patients with chronic nonunions (1.5 to 12 years), shortening of $2-12 \mathrm{~cm}$, defects of $1.5-10 \mathrm{~cm}$, and deformities of 15-40 degrees. After treatment by the infection and correction of deformity and shortening. The treatment time ranged from 9 to 16 months. In six patients, union was not achieved after one attempt, five united on the second attempt, and one had an amputation. $^{16}$

\section{CONCLUSION}

From this study we conclude that Ilizarov external fixator is a reliable, versatile and effective treatment for the treatment of tibia nonunion fractures.

Funding: No funding sources

Conflict of interest: None declared

Ethical approval: The study was approved by the institutional ethics committee

\section{REFERENCES}

1. Anderson G. Bone graft for delayed union and union of the tibia. J Bone Joint Surg. 1996;48:591.

2. Albert M. Delayed union in fractures of the tibia and fibula. J Bone Joint Surg. 1944;26:566.

3. Bier Mann JS, Nepola JV. A unilateral bone transport system for segmental defects of bone. Ortho Trans 1991;15:639.

4. Campbell WC. Onlay bone graft for ununited fractures. Arches Surg. 1939;58:13.

5. Campbell WC. Transf Surgerence of the fibula as an adjunct to free bone graft in the tibial deficiency. J Orthop. 1919;1:625.
6. Candle RJ, stern PJ. Severe open fractures of the tibia. J Bone Joint Srg. 1987;69:801.

7. Segmuller G. Diagnostic use of 85 strontium in the preoperative evaluation of nonunion. Acta orthop Scand. 1970;41:150.

8. Weber BG, Cech O. Pseudoarthrosis. Bem Hans Huber. 1976.

9. Rosen H. Compression treatment of long bone pseudarthroses. Clin Orthop.1979;138:154.

10. Paley D. Current techniques in limb lengthening. J Pediatr Orthop. 1988;8:73.

11. Paley D. Problems, obstacles and complications of limb lengthening by Ilizarov technique. Clin Orthop. 1990;250:81-104.

12. Milch H. Tibiofibular synostosis for non-union of the tibia. Surgery. 1950;27:770.

13. Lamb RH. Posterolateral bone graft for nonunion of the tibia. Clin Orthop. 1969;64:114.

14. Kummer FJ. biomechanics of the Ilizarov external fixators. Bull Hosp J Dis Ortho Inst. 1989;49:140.

15. Kojimoto $\mathrm{H}$, Yasui $\mathrm{N}$, Goto $\mathrm{T}$, Matsuda $\mathrm{S}$, Shimomura Y. Bone lengthening in rabbits by callus distraction. J Bone Joint Surg. 1988;70:543-9.

16. Voronovich IP, Volchkevich PL. The treatment of bony defects in the tibia by the Ilizarov method. In experimental theoretical and clinical aspects of osteosynthesis developed at the KNIEKOT. 2nd International Conference Abstracts, Kurgan, USSR; 1986: 116.

17. Aaronvich AM, Shyachov VI, Payevski SS, Lepyech Rempel GD, Berezovskaya TP, et al. Rehabilitation by Ilizarov technique of patients with bony defects of tibia complicated by chronic osteomyelitis. In experimental theoretical and clinical aspects of transosseous ostesynthesis developed at the KNILEKOT. 2nd International Conference Abstracts, Kurgan, USSR; 1986: 74.

Cite this article as: Reddy PD, Kumar KH. Analysis of results of nonunion tibial fractures Ilizarov external fixation. Int J Res Orthop 2018;4:698-701. 